\title{
PENGARUH KONSENTRASI GARAM TERHADAP VISKOSITAS SABUN CAIR BERBASIS SURFAKTAN ANIONIK
}

\section{The Effect of Salt Concentration on the Viscosity of Anionic Surfactant Liquid Soap}

\author{
Robby Sudarman ${ }^{1}$, Alisya Nurbaits ${ }^{2}$, Rony Pasonang Sihombing ${ }^{*}$ \\ ${ }^{1}$ Politeknik Negeri Bandung, Bandung \\ ${ }^{2}$ Politeknik Sekolah Tinggi Teknologi Tekstil Bandung, Bandung \\ email: rony.pasonang.sihombing@polban.ac.id
}

\begin{abstract}
Abstrak.Sabun cair merupakan salah satu jenis pembersih yang cukup banyak digunakan di dalam aspek kehidupan. Material ini berfungsi sebagai bahan penghilang kotoran dan lemak pada berbagai perkakas. Tujuan dilaksanakannya penelitian ini adalah untuk dasar pengaturan viskositas sabun cair bagi penelitianpenelitian selanjutnya. Surfaktan Sodium Lauril Sulfat (SLS) digunakan sebagai bahan baku utama dan garam $\mathrm{NaCl}$ sebagai pengatur viskositas. Konsentrasi $\mathrm{NaCl}$ yang digunakan dalam penelitian ini dimulai dari $0.45 \%$ wt hingga $2.2 \%$ wt. Metode yang digunakan adalah metode reaksi batch. Hasil penelitian menunjukkan terjadi peningkatan viskositas sabun cair dari $300 \mathrm{cps}$ hingga $5000 \mathrm{cps}$. Oleh karenanya, pengaturan viskositas dapat dilakukan dengan menggunakan konsentrasi garam sesuai kebutuhan.
\end{abstract}

Kata kunci:sabun cair, surfaktan, garam, viskositas

Abstract.Liquid soap is a type of cleanser that is quite widely used in several aspects of life. This material can be used for removing impurities in various tools. The purpose of conducting this research was to set the basic viscosity of liquid soap for future research. Sodium Lauryl Sulfate (SLS) was used as the main raw material and $\mathrm{NaCl}$ salt as viscosity controller. $\mathrm{NaCl}$ concentration used in this research was from $0.45 \%$ wt to $2.2 \%$ wt. The methods used was batch reaction. The results showed an increase of the liquid soap viscosity from $300 \mathrm{cps}$ to 5000 cps. Therefore, viscosity setting can be done by using salt concentration needed.

Keywords: liquid soap, surfactant, salt, viscosity

\section{PENDAHULUAN}

Sabun cair merupakan sabun yang berbentuk cairan serta memiliki beberapa kelebihan karena sifatnya yang movable dan relatif lebih higienis karena tersimpan di dalam tempat yang tidak terbuka setiap saat. Produk sabun cair ini berpotensi menjadi sebuah ide bisnis yang cukup strategis untuk dipasarkan (Hartanto, 2015). Di Indonesia, banyak usaha sabun cair dilakukan dengan menggunakan formulasi yang melibatkan jenis surfaktan dan elektrolit garam (Arwinda G, Njoo M P S, Aylianawati, 2013; Ruwana et al., 2018; Sumanto et al., 2016). 
Surfaktan merupakan molekul yang memiliki dua sisi yang terdiri dari bagian hidrofilik (polar, larut dalam air) dan hidrofobik (non polar, larut dalam minyak/ pelarut non-polar) (Tang, 2011). Secara skematis, molekul surfaktan ditunjukkan pada Gambar 1.

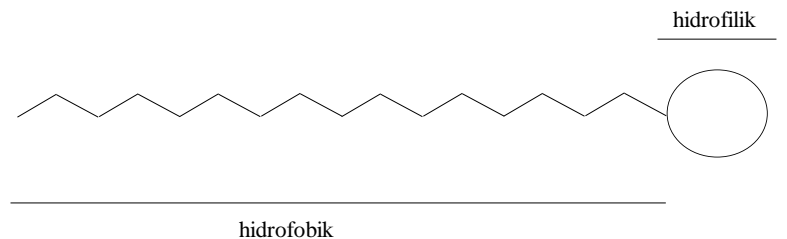

\section{Gambar 1. Skema surfaktan}

Dalam penelitian ini, surfaktan Sodium Lauryl Sulfate (SLS) digunakan. SLS merupakan jenis surfaktan anionik dengan muatan negatif pada bagian hidrofiliknya (Azmi \& Sajida, 2016). Secara skematis, struktur SLS dapat dilihat pada Gambar 2.

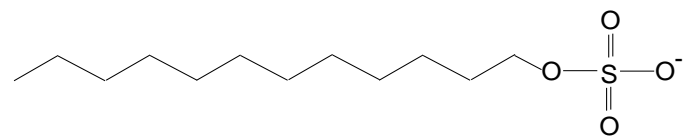

\section{Gambar 2. Skema surfaktan SLS}

Pada Gambar 2, dapat dilihat bagian muatan negatif pada bagian "O" yang nantinya akan memberi kelebihan tersendiri pada aplikasinya. Surfaktan SLS dipilih karena relatif mudah didapat di pasaran. Psda penelitian sebelumnya, surfaktan SLS ini berpengaruh besar pada densitas/ massa jenis (Handayani et al, 2018) dimana semakin besar jumlah SLS yang digunakan akan berdampak pada semakin besarnya massa jenis dari produk yang dihasilkan.

Sabun cair merupakan pembersih berbentuk cair dan memiliki bentuk menarik serta lebih praktis bila dibandingkan dengan sabun batang / sabun padatan (Sari \& Ferdinan, 2017). Aplikasi penggunaan sabun cair banyak digunakan pada industriindustri seperti hotel (Putra, 2015), sekolah (Darwin et al., 2018), keperluan rumah tangga (Wathoni et al., 2019), dan sebagainya. Beberapa senyawa digunakan untuk membuat jenis sabun cair ini. Diantaranya adalah surfaktan dan garam. Berdasarkan uraian diatas, maka penelitian terkait surfaktan dan garam diadakan untuk mengukur pengaruh garam terhadap karakter sabun cair, terutama pada tingkat viskositasnya.

Beberapa cara dapat dilakukan untuk membuat sabun. Pertama adalah dibuat dari asam lemak dan logam yang digaramkan. Cara lainnya adalah dengan membuatnya dari bahan dasar zat aktif permukaan/ surfaktan (Salamah et al., 2018). Pada penelitian ini, pembuatan sabun cair dilakukan dengan bahan dasar zat aktif permukaan.

\section{METODE PENELITIAN}

Penelitian dilakukan di Laboratorium Satuan Proses Politeknik Negeri Bandung. Bahan yang digunakan antara lain SLS (T\&T Chemical), NaCl (T\&T Chemical), aquades. Alat yang digunakan antara lain beaker glass (Pyrex), Hot Plate (IKA), magnetic stirrer. Proses pembuatan sabun cair diawali dengan pengadukan surfaktan SLS, aditif dan air hingga larutan menjadi homogen. Pengadukan tersebut dilakukan 
pada beaker glass. Kemudian $\mathrm{NaCl}$ dimasukkan sedikit demi sedikit hingga larut semua. Kondisi operasi yang digunakan adalah pengadukan antara $100-400 \mathrm{rpm}$ dengan menggunakan magnetic stirrer pada tekanan 1 atm dan suhu ruang $25^{\circ} \mathrm{C}-30^{\circ} \mathrm{C}$.

Setelah proses pembuatan selesai dilakukan, produk dibiarkan dulu selama 1 malam. Tujuannya adalah supaya produk dapat relaksasi dan lebih stabil ketika saat pengukuran. Sehingga adanya perubahan karakter dapat diminimalisir pada tahap berikutnya. Pada tahap berikutnya, karakterisasi dilakukan untuk mengetahui hasil produk yang dibuat. Karakterisasi dilakukan dengan mengukur viskositas dalam kondisi suhu ruangan $\left(25^{\circ} \mathrm{C}\right)$ dengan menggunakan viskometer Brookfield. Viskositas merupakan parameter penting bagi sabun cair untuk penggunaan aplikasinya(Anggraeni et al., 2020). Secara umum, gambaran percobaan ditunjukkan pada Gambar 3.

1. Beaker glass

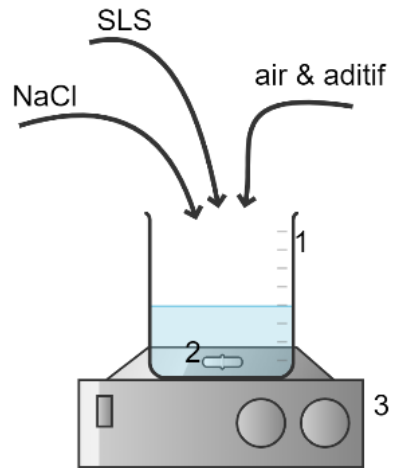

2. Stirrer

3. Magnetic stirrer

\section{HASIL PENELITIAN DAN PEMBAHASAN}

Pengaruh Konsentrasi Garam terhadap Viskositas Sabun Cair

Pembuatan sabun cair dilakukan dengan 4 jenis konsentrasi garam $\mathrm{NaCl}$. Dimulai dari konsentrasi $0.45 \%$ hingga $2.2 \%$. Hasil dari pembuatan sabun dapat dilihat pada Gambar 4. Berdasarkan data, ada kecenderungan peningkatan viskositas dengan meningkatnya konsentrasi garam $\mathrm{NaCl}$. Pada konsentrasi $0.45 \%$, viskositas sabun cair yang dihasilkan adalah 380 cps. Ketika konsentrasi ditingkatkan menjadi $0.9 \%$, peningkatan viskositas menjadi $400 \mathrm{cps}$. Titik kesetimbangan terjadi pada konsentrasi garam $\mathrm{NaCl}$ di angka $1.34 \%$ dimana setelah konsentrasi itu viskositas meningkat dengan tajam. Pada salah satu literatur, disebutkan bahwa hasil viskositas sabun cair yang didapat adalah sekitar 2000 cps (Anggraeni et al., 2020) dimana angka ini masih dalam jangkauan viskositas yang dihasilkan pada penelitian ini. 


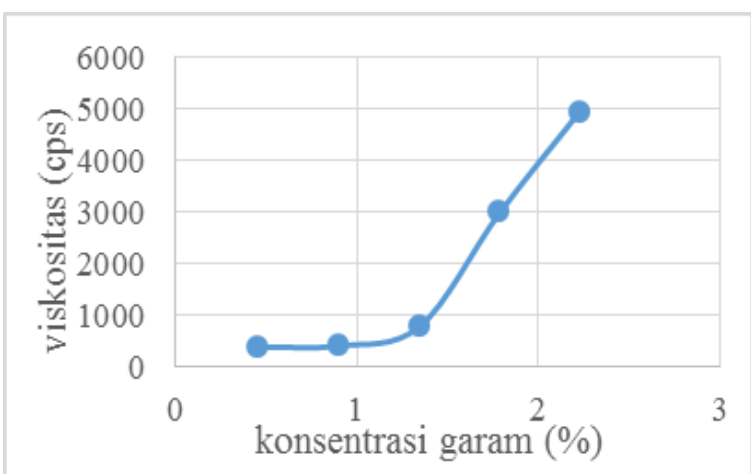

Gambar 4. Konsentrasi sabun cair dengan Jumlah Garam NaCl

Adanya penggunaan surfaktan anionik pada air menyebabkan senyawa surfaktan itu sendiri berubah dan membentuk misel dengan muatan negatif seperti yang diilustrasikan pada Gambar 5. Dengan adanya penambahan garam yang bermuatan positif $\left(\mathrm{Na}^{+}\right)$, bentuk spherical misel ini menjadi memanjang dan berubah bentuk menjadi bentuk misel silinder seperti pada ilustrasi Gambar 6. Setelah membentuk misel silinder panjang, ikatannya menjadi terjerat satu sama lain sesuai ilustrasi skema pada Gambar 7. Hal inilah yang menyebabkan adanya peningkatan viskositas saat penambahan garam $\mathrm{NaCl}$.

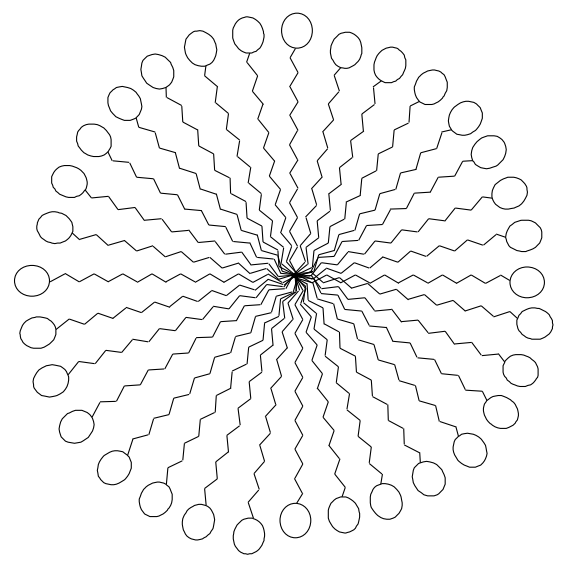

Gambar 5. Skema bentuk misel 


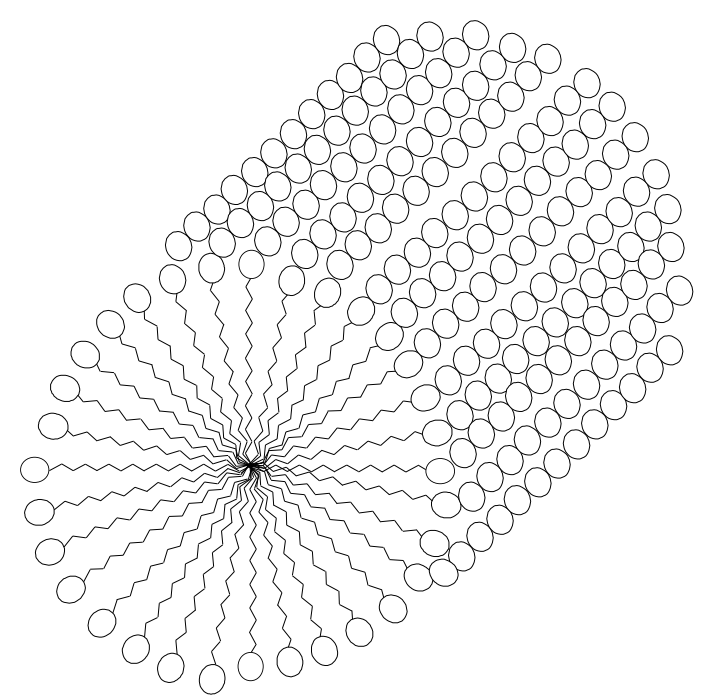

Gambar 6. Skema bentuk misel silinder

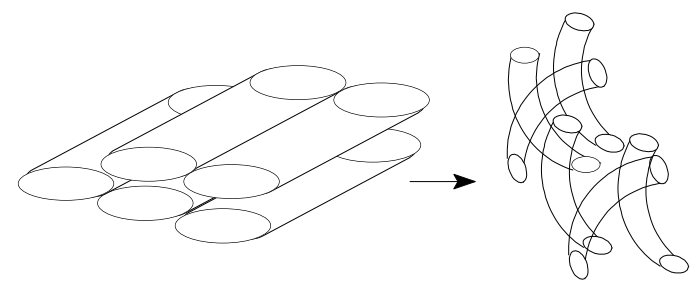

Gambar 7. Kiri: Skema misel silinder panjang, Kanan: Skema misel yang terjerat satu sama lain

\section{SIMPULAN}

Sabun cair berbasis surfaktan anionik telah berhasil disintesis dengan berbagai konsentrasi garam $\mathrm{NaCl}$. Penambahan garam $\mathrm{NaCl}$ mengakibatkan peningkatan viskositas pada sabun cair itu sendiri. Konsentrasi garam $0.5 \%$ wt menghasilkan viskositas sebesar 300 cps dan konsentrasi garam $2.2 \%$ wt menghasilkan viskositas sebesar $5000 \mathrm{cps}$.

Dengan adanya penelitian ini, diharapkan dapat dijadikan dasar yang terukur oleh penelitian-penelitian berikutnya dalam pembuatan sabun cair yang melibatkan garam dan surfaktan anionik. Sehingga output yang dihasilkan dapat lebih bervariasi.

\section{DAFTAR RUJUKAN}

Anggraeni, Y., Nisa', F., \& Betha, O. S. (2020). Karakteristik Fisik dan Aktivitas Antibakteri Sabun Cair Minyak Nilam (Pogostemon cablin Benth.) yang Berbasis Surfaktan Sodium Lauril Eter Sulfat. Jurnal Kefarmasian Indonesia, 0, 1-10.

Arwinda G, Njoo M P S, Aylianawati, N. I. (2013). Pembuatan sabun dengan lidah buaya (Aloe Vera) sebagai Antiseptik Alami. Widya Teknik, 12(1), 11-21.

Azmi, L., \& Sajida, G. N. (2016). Pengaruh Penambahan Surfaktan Terhadap Kestabilan Emulsi Solar-Air Sebagai Bahan Bakar Aletrnatif pada Mesin Diesel. Skripsi 
Dalton : Jurnal Pendidikan Kimia dan Ilmu Kimia, Volume 4 Nomor 1, Mei 2021

Fakultas Teknologi Industri Institut Teknologi Sepuluh November Surabaya, 14.

Darwin, R., Widiarsih, D., Murialti, N., Hidayat, M., Hadi, M. F., \& Asnawi, M. (2018). Menumbuhkan Jiwa Wirausaha Siswa Dan Guru Sekolah Menengah Kejuruan (Smk) Pgri Pekanbaru Melalui Pelatihan Pembuatan Sabun Cuci Piring Cair. Jurnal Pengabdian UntukMu NegeRI, 2(1), 10-16.

Hartanto, S. (2015). Peluang produk fragrance sabun di pasar nigeria. Market Brief, 5, Indonesian Trade Promotion Centre Lagos: Lagos. Av.

Putra, fiko nanda. (2015). Prosedur Membersihkan Area Lounge Bar Dan Peralatan Bar Di Hotel Berbintang Kota Padang. 151(September), 10-17.

Ruwana, I., Widodo, B., \& Sudiasa, N. (2018). Pembuatan Sabun Di Desa Torongrejo. Jurnal Teknik Industri, I(September), 43-46.

Salamah, S., Sulistiawati, E., \& Aktawan, A. (2018). Pelatihan Teknologi Kimia Terapan Pembuatan Sabun Cair Cuci Piring, Sabun Mandi Herbal Dan Tepung Ampas Kelapa Ibu-Ibu 'Aisyiyah Ranting Perumnas Condong Catur, Depok, Sleman. Jurnal Pemberdayaan: Publikasi Hasil Pengabdian Kepada Masyarakat, 1(2), 465.

Sari, R., \& Ferdinan, A. (2017). Pengujian Aktivitas Antibakteri Sabun Cair dari Ekstrak Kulit Daun Lidah Buaya. Pharmaceutical Sciences and Research, 4(3), 111-120.

Sri Handayani; Nurul Hidayati; Rian Vani. (2018). Formulasi Sabun Mandi Cair Ekstrak Kulit Jeruk Manis Varietas Siam (Citrus Sinensis L.) Dengan Variasi Konsentrasi Surfaktan Sodium Lauril Sulfat. CERATA - Jurnal Ilmu Farmasi, 10, 7-19.

Sumanto, Adriantantri, E., Utomo, A., \& Widodo, B. (2016). Pembuatan Sabun Cair di Tlogomas Malang. Seniati, 157-161.

Tang, M. (2011). Pengaruh Penambahan Pelarut Organik Terhadap Tegangan Permukaan Larutan Sabun. Simposium Nasional Inovasi Pembelajaran Dan Sains (SNIPS).

Wathoni, M., Susanto, A., Kirana, A., \& Putri, D. (2019). Pemanfaatan Bahan Rumah Tangga dalam Pembuatan Sabun Cair dari Sabun Batang di Masa Pandemi. Seminar Nasional Pengabdian Masyarakat LPPM UMJ, 1-6. 